\title{
Topics
}

Mohsen Javdani*

\section{Noise or News? Learning about the Content of Test-Based School Achievement Measures}

\begin{abstract}
Test-based measures of school performance are increasingly used to inform both education policy and families' school choice decisions. There are, however, concerns about the reliability of these measures. This paper assesses the extent to which cross-sectional differences in schools' average achievement on standardized tests reflect transitory factors, using data from a 1999-2006 panel of public and private schools in British Columbia, Canada. Sampling variation and one-time mean reverting shocks are shown to be significant sources of cross-sectional variation in schools' mean test scores. The results therefore suggest that public dissemination of information about schools' average achievement on standardized tests could potentially mislead or confuse parents. These results should also encourage caution in the design of policies that attach monetary or nonmonetary rewards or sanctions to schools on the basis of test-based achievement and suggest a need for more sophisticated measures of school performance.
\end{abstract}

Keywords: education, test-based school achievement measures, school choice decisions, transitory factors

DOI 10.1515/bejeap-2014-0052

\section{Introduction}

Proponents of school choice argue that the structure of the public educational system - where education is mainly provided by government with substantial monopoly power and largely no competition - leaves parents with limited choice among schools. They suggest that this may result in a disconnect

*Corresponding author: Mohsen Javdani, Department of Economics, University of British Columbia, Okanagan Campus, Kelowna, BC, Canada V1V 1V7, E-mail: mohsen.javdani@ubc.ca 
between school quality and parents' preferences. A growing literature in economics suggests that education reforms that expand school choice for students (e.g. open enrollment systems, magnet and charter schools, private school vouchers, and expanded public school choice for students in poorly performing schools) could improve educational outcomes such as test scores, educational attainment, expenditures, efficiency, etc. They argue that expanding school choice will improve access to higher quality schools, especially for relatively disadvantaged children. Moreover, expanding options for students will induce competition in education market that will put pressure on poorly performing schools to either improve their performance or to shrink as families "vote with their feet" (Friedman 1955; Borland and Howsen 1992; Becker 1995; Dee 1998; Hoxby 2003; Belfield and Levin 2003, Misra, Grimes, and Rogers 2012). ${ }^{1}$

One suggested approach to make these policies more effective is to increase parents' access to information about school quality and performance so they can benefit from the opportunity to attend sought-after schools (e.g. Lai, Sadoulet, and de Janvry 2009, Allen and Burgess 2013). ${ }^{2}$ A growing body of evidence suggests that test-based information about school performance affects parents' school choice decisions and could consequently have real impacts on students' educational outcomes (e.g. Hastings, Van Weelden, and Weinstein 2007; Hastings and Weinstein 2008; and others). A more recent study by Friesen et al. (2012) examines the effect of the public release of information about school achievement on parental choice behavior. Using data that is very similar to this study, they find that the public release of test-based information about school achievement substantially affects the mobility decisions of students in the Lower Mainland of British Columbia, Canada. ${ }^{3}$ Their results suggest that some parents respond to information soon after it is publicly disseminated, and continue to respond to subsequent releases in the following years. However, it remains an open question and a concern whether test-based measures of school achievement, that are one of the main factors that affect student mobility, actually

1 However, it should be also mentioned that there are some concerns regarding these types of policies. For instance, some people argue that education reforms that try to expand school choice will ignore issues of equity which will create more risks for disadvantaged students.

2 For instance, Manski (1992) argues that "a market for schooling cannot be expected to perform as promised by advocates of choice unless society and families are adequately informed about the education provided by the schools."

3 Lower mainland is a large metropolitan area with a population of approximately 2.5 million that includes the city of Vancouver and its suburbs (Friesen et al. 2012). As it is explained in more detail below, our paper uses data for the entire province of British Columbia, which also contains the Lower Mainland region (more than $50 \%$ of the population of $\mathrm{BC}$ reside in the Lower Mainland region). 
provide parents with meaningful information about school quality and performance, or whether they are too imprecise to do so. This is especially important in jurisdictions, such as the one studied by Friesen et al. (2012) and this paper, where publicly disseminated test-based information about schools gets updated annually and is found to be one of the important factors that affects parents' school choice decisions and education policy.

The imprecision in test-based school achievement measures also has important implications for jurisdictions with school accountability systems. As Kane and Staiger (2001, 2002b) also point out, to the extent these test-based school achievement measures are used in school accountability systems to evaluate schools' performance, high degree of imprecision in these measures can wreak havoc in school accountability systems and subject schools to sanctions or rewards based on factors that are beyond their control. ${ }^{4}$ Moreover, to the extent these measures are used to identify best strategies of school reform, the imprecision in these measures could mislead policy makers and educational authorities in their evaluation of the merits of different education practices.

Kane and Staiger (2001, 2002a) suggest two potential sources of transitory variation in school average test scores. The first is sampling variation, which is a purely statistical phenomenon. Different cohorts of students attending a school in different years can be considered as random samples drawn from a local supplying population. Therefore, there will be year-to-year variation in a school's test score solely arising from random year-to-year variation in the composition of its student body (i.e. sampling variation). The magnitude of sampling variation depends on school size: it is decreasing in the number of students who write the test. Since the enrollment is usually quite small in an average elementary school (41 in grade 4 and 50 in grade 7 in our sample) the variation induced by sampling variation could be quite serious. The second source of transitory variation is idiosyncratic factors that generate non-persistent differences in schools' mean test scores; for example, a school-wide illness at the time of the exam, the presence of a few troublemaking students in a class, teacher absenteeism due to personal issues, etc. Following Kane and Staiger (2001, 2002a), we refer to this second source of transitory variance as "other transitory factors" to distinguish it from sampling variation.

There is evidence that suggests mobility decisions could be costly for students and their parents and might not contribute much to students' academic performance. Cullen, Jacob, and Levitt (2005) find little or no evidence that

4 This might be less of a concern in jurisdictions where more sophisticated and a wider variety of test scores and sometimes non-test-based measures are used to evaluate schools' performance. 
students systematically achieve higher school quality (measured by value-added of schools to student outcomes) by choosing a non-neighborhood school. Their results also suggest that the main effect of Chicago's open-enrollment program has been to induce segregation. Kane and Staiger (2001) find little evidence that schools with significant improvement in their test scores over time improved on any measures of student engagement. Hanushek, Kain, and Rivkin (2004) find that mobility generates negative externalities for students that entail a substantial cost for movers and non-movers alike. Cullen, Jacob, and Levitt (2006) exploit randomized lotteries that determine high-school admission and find little evidence that lottery winners (who attend what appear to be substantially better high schools; e.g. schools with higher achievement levels (and gains), higher graduation rates, and lower poverty rates) receive any benefits across a wide variety of traditional academic measures (e.g. standardized test scores, graduation, attendance rates, course-taking patterns, and credit accumulation). They also find some disadvantages associated with winning a lottery and therefore attending schools with higher achieving peers, such as lower class ranks throughout high school and higher chances of dropping out.

Wolf et al. (2007) study the federally sponsored voucher program in Washington, DC, and find that using a voucher to attend a private school had no impact on average reading or math scores. Mayer et al. (2002) also find similar results using experimental voucher evidence from New York City. Using data from 150 municipalities in Chile, Hsieh and Urquiola (2006) find that communities where private schools grew by more after the introduction of a comprehensive school voucher program did not experience a faster increase in their average test score, and in fact had worse average repetition and grade-foraverage measures. Consistent with the findings of Cullen, Jacob, and Levitt (2005) and Fiske and Ladd's (2001), they also find evidence that similar voucher programs led to increased segregation. Booker et al. (2007) study the impact of charter school attendance in Texas and find that students attending a charter school experience a poor test score growth in their initial year and it takes about 3 years for them to recover from this initial disruption. Bifulco and Ladd (2006) examine the performance of charter schools in North Carolina and find that students in charter schools make considerably smaller achievement gains than they would have in public schools. Their results attribute $30 \%$ of the negative effect of charter schools to high student turnover rates. ${ }^{5} \mathrm{~A}$ related literature

5 It should be mentioned that evidence on academic effectiveness of charter schools is mixed. There are also studies that suggests attending a charter school could have a positive impact on students' performance, especially after they mature and gain more experience (e.g. Hoxby and Rockoff 2005; Hoxby and Murarka 2007; Sass 2006; Witte et al. 2007, and others). Therefore, we 
examines the effect of information about school-average achievement on real estate prices (Black 1999; Gibbons and Machin 2003; Kane et al. 2003, Figlio and Lucas 2004; Kane and Staiger 2006, Fiva and Kirkebøen 2010; Ries and Somerville 2010; and others). These studies generally find a positive relationship between information about school performance and housing prices.

We investigate the content of publicly disseminated information about schools' average test scores to determine whether they provide parents with meaningful information about persistent inter-school differences in achievement and school quality. Since there is evidence that suggests test-based school achievement measures are one of the factors that shape parents' mobility decisions, and since the studies reviewed above suggest that these decisions could be costly with negative, weak, or no academic benefits to students, it is important to investigate the degree of imprecision in these test-based measures that could contribute to parents' mobility decisions. If these decisions are heavily based on noisy measures of school achievement, they could impose a substantial cost on parents and make them and their child considerably worse off. Moreover, making costly location decisions to obtain access to (currently) high-achieving schools could generate a lot of costly churning in the real estate market, and again making families worse off.

This is particularly important since Friesen et al. (2012) find that "parents in low income neighborhoods are most likely to alter their school choice decisions in response to new information [that is based on test-based school achievement measures that we are also examining in this study]." These are potentially families that are less likely to obtain information about school quality through other sources (for example due to their more limited access to well-informed networks) and are therefore more likely to put a large weight on these test-based measures to inform their school choice decisions. Moreover, given their socioeconomic background, mobility decisions are potentially more costly for these families and will more negatively affect them if they are heavily shaped by highly transitory information about school-average achievement.

Finally, if test-based measures of school achievement are strongly influenced by transitory factors, to the extent they are consulted to identify best practices in education, they will only confuse or mislead policy makers and educational authorities, which could be also quite costly. It should be

are not suggesting that mobility decisions made by parents are always costly and without academic benefits to students. Our argument is that there is considerable amount of evidence that suggests these mobility decisions could be costly and have negative or no impact on students' academic performance, and therefore there is room for concern regarding imprecision in test-based measures that shape these decisions. 
emphasized that the use of test-based accountability systems is also one of the important motivations behind examining the degree of imprecision in test-based school achievement measures. However, since in British Columbia (BC), and in Canada in general, there are currently no test-based school accountability systems, our main motivation for this study is the effect of test-based information on parents' school choice decisions. This is particularly important in the jurisdiction under study, British Columbia, where school choice has been one of the priorities of the provincial government and the commitment to it is mentioned as part of the BC education plan. ${ }^{6}$

We extend the work of Kane and Staiger (2002a) by laying out a more rigorous statistical model that shows more clearly the underlying model and the assumptions under which one can separately measure the effect of sampling variation and other transitory factors on the cross-sectional variance of school mean test scores. We find that sampling variation and other transitory factors are a significant source of observed variation in schools' average test scores even among substantially large schools, and pooling student test scores across grades and years to dampen the volatility does not resolve this issue.

\section{Previous Literature}

Not much is known about the statistical properties of school-level measures of test-based achievement. Kane and Staiger (2001) find that test-based elementary school rankings in North Carolina resemble a lottery and argue that small within-school sample size that exacerbates the sampling variation is the main cause. Using methods developed by McClellan and Staiger (1999) for the analysis of hospital performance measures, they estimate that for an elementary school of average size in North Carolina, $28 \%$ and $10 \%$ of the variance in grade 5 reading scores is due to sampling variation and other transitory factors,

6 Following its commitment to expand school choice, starting July 2002, BC’s Ministry of Education instituted an official "open boundaries" policy that allows students to attend any public schools outside their catchment area. A recent study by Friesen, Harris, and Woodcock (2013) suggests that "many parents have embraced the school choice opportunities the new rules created. The share of students enrolled out of catchment started to increase in the first year after the new policy came into effect. By the 2006/07 school year, an additional 5.8\% of the children living in British Columbia's 14 Lower Mainland public school districts were attending out-of-catchment public schools. This response to open enrolment has reinforced the decline in catchment school enrolment that was already underway as a result of growth of enrolment in private schools and French Immersion programs.” 
respectively. They also decompose the variance of school-level test scores and find that gain scores tend to have "less signal variation and more variation due to non-persistent factors" than test score levels. Therefore, they caution against the use of gain scores in evaluating schools' or teachers' performance.

Using data from North Carolina, Kane and Staiger (2002a) examine the effect of sampling variation and other transitory factors on between-school variance in the average test scores, gain scores, and changes in the average test scores between 2 consecutive years. They estimate that for an average school in their sample, sampling variation is responsible for $14-15 \%$ of the variation in fourthgrade mean math and reading test scores. They also find that the effect of sampling variation on between-school variance in average gain scores (i.e. changes in student's test scores between two consecutive grades in a given school) is twice as large as that of average test score levels. For schools of different size, they find that transitory factors explain 10-20\% of the betweenschool variance in combined reading and math scores in grade 4, 28-58\% of the variance in gains between third- and fourth-grade scores, and $73-80 \%$ of the variance in annual change in fourth-grade scores.

Mizala, Romoguera, and Urquiola (2007) find evidence that test-based rankings mostly reflect socioeconomic status. They also argue that the more highly correlated are test-based achievement and socioeconomic status, the lower is the year-to-year volatility in rankings based on test-based school achievement measures. Finally, using evidence from Chile's P-900 program, Chay, McEwan, and Urquiola (2005) show that noise and mean-reverting shocks in schools' test scores complicate evaluation of policies to improve school's quality. They find that for a median-sized school, 33\% and 21\% of the variance in language and math scores, respectively, are due to transitory factors. They argue that such noise in mean test scores might limit the ability to identify "good" schools from "bad" schools.

\section{A Simple Model}

It is often costly to determine school quality, which makes school choice decisions difficult for parents. Although a parent seeking information about a school's quality might choose to meet the principal, speak with neighbors, and visit the facilities, idiosyncrasies in the fit between child and school make true quality difficult to observe. In the absence of perfect information, parents must therefore form beliefs about school quality and base their school choice decisions on those beliefs. Recent studies suggest that signals received by parents in form of school-level test-based achievement measures play an important role in shaping these decisions. 
We present a simplified model of school choice that accounts for uncertainty about school quality and focuses attention on the effects of noisy information based on school average test scores. ${ }^{7}$ Assume parent $i$ 's utility $\left(U_{i s}\right)$ depends on the quality $\left(q_{s}\right)$ of their child's school $s$,

$$
U_{i s}=q_{s}+\varepsilon_{i s}
$$

where $q_{s}$ represents an index of school characteristics that determines parents' utility, such as teacher quality, peer quality, school's state of technology, and class size. $\varepsilon_{i s} \sim N\left(0, \sigma_{\varepsilon}^{2}\right)$ represents how utility of individual $i$ from school $s$ differs from the tastes of the average individual. We assume that parents don't observe $q_{s}$. Given the characteristics of a school that are observed prior to any test-based information, parents hold a prior about the quality of school that is normally distributed with mean $X_{s}^{\prime} \beta$ and precision $h_{q i}$ (i.e. $q_{s} \sim N\left(X_{s}^{\prime} \beta, h_{q i}^{-1}\right)$. This suggests that parents use $X_{s}^{\prime} \beta$, their expectation of the distribution, as their guess for the quality of school, where $X_{s}^{\prime} \beta$ is a combination of directly observable school characteristics $X_{s}$ such as neighborhood income and the demographic composition of the student body, and $\beta$ is the vector of weights that parents assign to these characteristics. The precision of the prior is known to parents and is the same across schools in parents' choice set. However, it is allowed to vary across parents to reflect the idea that some (e.g. new immigrants) may have less precise beliefs about school quality than others (e.g. a native born individual who has lived in the area for many years).

If observed school characteristics are the only source of information about school quality for parents, a parent chooses school $s$ if

$$
E\left[U_{i s} \mid X_{S}^{\prime} \beta\right]-c_{i s}>E\left[U_{i k} \mid X^{\prime}{ }_{k} \beta\right]-c_{i k} \quad \forall k \in \Sigma, k \neq s
$$

where $c_{i s}$ measures the direct (e.g. tuition) and indirect (e.g. commuting distance) costs of attending school $s$. Given the assumptions made before, this implies that the average parent chooses school $s$ if

$$
X_{s}^{\prime} \beta-c_{i s}>X_{k}^{\prime} \beta-c_{i k} \quad \forall k \in \Sigma, k \neq s
$$

Now suppose that parents also receive a noisy signal $S_{s}$ regarding school's quality,

$$
S_{s}=q_{s}+\eta_{s}
$$

7 The notation is adapted from Moretti (2008), where a similar model is used to study peer effects in movie consumption. Friesen et al. (2012) adopt a similar model to study the effect of new information about school quality on parents' school choice decisions. 
where $\eta_{s} \sim N\left(0, h_{\eta i s}^{-1}\right)$. We have in mind that the signal is based on standardized test scores aggregated to the school level. The noise component of the signal $\eta_{s}$ has zero mean, implying that test scores provide unbiased information about school quality. The true precision of test scores as a signal of school quality, $h_{\eta i s}$, varies across schools and parents. This reflects the idea that the precision of average test scores depends on the extent to which they are influenced by sampling variation and other transitory factors, and therefore varies across schools. The precision of average test scores is also allowed to vary across parents reflecting the possibility that different parents might have different perceptions regarding the precision of average test scores as a signal of school quality, which is influenced by factors such as parents' socioeconomic background, access to well-informed social networks, etc. We assume parents do not observe the true precision of average test scores, $h_{\eta i s}$, since parents cannot perfectly measure the extent to which these test scores are influenced by transitory factors. Moreover, for a given parent, the precision of test scores as a signal of school quality is the same across different schools, since parents cannot measure how the effect of transitory factors on average test scores varies across schools. Therefore, for parent $i, \eta_{s} \sim N\left(0, h_{\eta i}^{-1}\right), \forall s \in \Sigma$.

Parents are assumed to assimilate new information via Bayesian learning. ${ }^{8}$ After observing the test-based signal, parents update their expectations about each school's quality using Bayes' rule. Since the true signal precision, $h_{\eta i s}$, is not known to parents, they update their expectation using what is known to them regarding the precision of signal, $h_{\eta i}$. Therefore, the normal learning model indicates that the expected quality of school $s$ for the representative parent after receiving the signal is

$$
m_{s}=E\left[q_{s} \mid X_{s}^{\prime} \beta, S_{s}\right]=\frac{h_{q i}}{h_{q i}+h_{\eta i}} X_{s}^{\prime} \beta+\frac{h_{\eta i}}{h_{q i}+h_{\eta i}} S_{s}
$$

Equation [5] suggests that parents' revised expectation of school quality is a precision-weighted average of the signal and their prior expectation; the more optimistic a parent's perception of precision of test scores as a signal of school quality relative to prior information, the greater the weight that parent would place on test scores. Prior information regarding school quality, $X_{s}^{\prime} \beta$, will continue to dominate the beliefs about school quality for parents who believe test scores are not a good signal of school quality (parents with low $h_{\eta i}$ ).

8 For recent applications of Bayesian learning, see Moretti (2011), Ichino and Moretti (2009), Erdem and Keane (1996), Altonji and Pierret (2001), Lange (2007), Chernew et al. (2001), and Woodcock (2010). 
Defining $\theta=h_{\eta i}\left(h_{\eta i}+h_{q i}\right)^{-1}$ as the weight that parents assign to test scores, and rearranging eq. [5], we can write the representative parent's expected utility as

$$
E\left[U_{i s} \mid X_{s}^{\prime} \beta, S_{s}\right]=\theta\left(S_{s}-X_{s}^{\prime} \beta\right)+X_{s}^{\prime} \beta
$$

We can define $S_{s}^{*}=\left(S_{s}-X_{s}^{\prime} \beta\right)$ to be the test score "shock," which represents the new information the signal $S_{s}$ provides to parents beyond what they already knew. Parents will now choose to enroll their child in school $s$ if

$$
\theta\left(S_{s}^{*}-S_{k}^{*}\right)>\left(X_{k}^{\prime}-X_{s}^{\prime}\right) \beta-\left(c_{i k}-c_{i s}\right)
$$

Since parents cannot distinguish between schools in terms of precision of their average test scores as a signal of school quality, the weight they assign to test scores, $\theta$, is the same for different schools. This lack of knowledge about the true precision of test-based signals, and the difference in precision of test scores across schools might hinder parents' ability to make the optimal decision. For instance, given the true precision of test-based signals, if signals received for school $s$ and $k$ are not equally precise and informative (i.e. $\theta_{s} \neq \theta_{k}$ ), we could have

$$
\left(\theta_{s} S_{s}^{*}-\theta_{k} S_{k}^{*}\right)<\left(X_{k}^{\prime}-X_{s}^{\prime}\right) \beta-\left(c_{i k}-c_{i s}\right)
$$

where $\theta_{s}=h_{\eta i s}\left(h_{\eta i s}+h_{q i}\right)^{-1}$ and $\theta_{k}=h_{\eta i k}\left(h_{\eta i k}+h_{q i}\right)^{-1}$. This suggests that the optimal decision is to choose school $k$ over school $s$, while due to lack of knowledge regarding the true precision of test-based signals, as eq. [7] suggests, it might seem optimal to choose school $s$ over school $k$. Even if the signals received regarding the quality of school $s$ and $k$ are equally precise, but parents' perceived precision of the signal is larger than the true precision of the signal (i.e. $\theta_{s}=\theta_{k}<\theta$ ), we could get a similar result. Therefore, the larger the effect of transitory factors on test-based school achievement measures, the higher the probability that parents school choice decision will be misled by this information and they become worse off. It is important not only to know the degree of imprecision in test-based signals of school quality, but also to be able to compare this degree of imprecision across schools in the choice set. For instance, if small schools tend to experience higher volatility in their average test scores due to transitory factors, and if parents are not well-informed about this, it could lead to schools choice decisions that are not optimal to make. ${ }^{9}$

9 It should be reminded again that as the model suggests, test-based school achievement measures are only one of the important factors based on which parents make school choice decisions. As the model suggests, the extent to which one factor dominates another has to do with the weights parents put on different factors. 


\section{Institutional Background and Data}

\subsection{Testing and Information}

Since the 1999/2000 school year, all public and provincially funded private schools in the province of $\mathrm{BC}$ have been required to administer standardized Foundation Skills Assessment (FSA) exams to students in Grades 4, 7, and 10 in May of each year. Students are examined in reading comprehension, writing, and numeracy. ${ }^{10}$ The Ministry of Education first provided individual and provincial-, district-, and school-level FSA exam results to schools in fall 2000 and instructed them to share the information with parents upon request (B.C. Ministry of Education 2000). The results of the 1999/2000 and 2000/2001 FSA exams were first posted on the Ministry's website in October 2001 (B.C. Ministry of Education 2001) and were found to have a substantial impact on mobility decisions (Friesen et al. 2012). ${ }^{11}$ Each subsequent set of FSA results has been posted the following fall.

The Fraser Institute, an independent Canadian public policy research and educational organization (Fraser Institute 2015), started publishing annual "report cards" on BC's elementary schools in June 2003 (Cowley and Easton 2003). These include school scores constructed by the Fraser Institute from FSA exam results, and rankings based on these scores. ${ }^{12}$ From the outset, the Fraser Institute's school report cards have received extensive media coverage.

As it was mentioned before, Friesen et al. (2012) examine the effect of this public release of information about school performance, by the Ministry of Education and the Fraser Institute, on school choice decisions (i.e. probability of separation from current school). They find that "English-speaking parents in low-income neighborhoods respond to the first release of information [by the

10 The FSA exams do not contribute to students' academic records and play no role in grade completion, and there are no financial incentives for teachers or schools related to student performance.

11 For instance, Friesen et al. (2012) report that, among families that speak English at home, one standard deviation increase in the 1999/2000 and 2000/2001 FSA scores relative to other schools reduced students' separation probability by 1.3 and 1.1 percentage points, respectively. 12 The Fraser Institute assigns a score to each school, on a scale from 0 to 10 , based on following indicators: school average FSA scores in grade 4 and grade 7 in reading, writing, and numeracy (provided by the Ministry of Education), the average gap between boys and girls in FSA scores on grade 7 reading and numeracy exams, percentage of all the completed tests written by those students who did not "meet expectations" according to provincial standards (see Cowley and Easton (2008) for more details), and percentage of students who did not write the tests. 
ministry of education] and continue to respond to subsequent releases in later years [by the ministry of education and the Fraser Institute].” These ongoing responses by parents could raise serious concerns if these test-based school achievement measures that are publicly released to parents are strongly influenced by transitory factors. ${ }^{13}$.

\subsection{Data}

The student-level data used in this study are derived from two administrative files maintained by the BC Ministry of Education: an enrollment database and an FSA exam database. The two databases are linked by a unique student identifier. Records in the enrollment database are based on an annual enrollment form collected on September 30 of each year for all students in the public and private school system between 1999 and 2006. It includes personal characteristics including gender, aboriginal status, home language, English as a second language (ESL) status, special education status, and postal code. ${ }^{14}$ We use the postal code information to augment the raw data with selected characteristics of each student's neighborhood as measured in 2001 and 2006 Canadian Census of Population at the Dissemination Area (DA) level. ${ }^{15}$ These proxy for parental income, education, and demographic information not measured in the administrative data.

All students who were registered in grade 4 or grade 7 in a BC public or private school between the 1999/2000 and 2006/2007 school years are included in the FSA exam database. This database includes the grade 4 and grade 7 reading and numeracy exam results in each year for students who wrote the test. For those who did not write, it includes an indicator of whether or not the student was excused from the test or was merely absent.

13 One point might worth emphasizing here. In this paper we only measure the effect on sampling variation and other transitory factors one school-level FSA test scores, and not on school-level measures constructed by the Fraser Institute. This is because the Fraser Institute scores are school-level measures, and as it will become clear below, we need student-level data to separately measure the effect of sampling variation and other transitory factors. However, given the importance of the Fraser Institute measures in influencing student mobility found by Friesen et al. (2012), especially among families that do not speak English at home, we also measure the proportion of cross-sectional variance in the Fraser Institute's school-level scores that is driven by transitory factors (Table 4 summarizes these results).

14 A postal code is an area as small as one side of the street on a city block in urban locations. $15 \mathrm{DA}$ is the name given to a relatively stable area targeted to contain 400-700 people. 
Our final sample includes all public and private schools that have valid average FSA reading and numeracy scores in all 8 years (1999-2006) and have more than five students in enrollment with non-missing FSA scores. ${ }^{16}$ Individual test scores in each year are normalized using overall mean and standard deviation for 1999-2006. Table 1 provides summary statistics for some variables of interest. There are 1,067 grade 4 schools and 798 grade 7 schools in our sample. Among schools that offer grade 4 and meet our sample restriction, $87 \%$ are public and $13 \%$ are private. For grade 7 , the numbers are

Table 1: Sample characteristics: grade 4 and grade 7 schools with valid FSA test scores between 1999 and 2006.

\begin{tabular}{|c|c|c|}
\hline Variable & $\begin{array}{r}\text { Grade } 4 \\
\text { Sample \% }\end{array}$ & $\begin{array}{r}\text { Grade } 7 \\
\text { Sample \% }\end{array}$ \\
\hline Number of schools in each year & 1,067 & 798 \\
\hline$\%$ Public schools & $87 \%$ & $84 \%$ \\
\hline$\%$ Private schools & $13 \%$ & $16 \%$ \\
\hline Average enrollment & 41 & 50 \\
\hline \multicolumn{3}{|l|}{ School-level average proportion of students: } \\
\hline Excused from reading test & $4.4 \%$ & $4.1 \%$ \\
\hline Excused from numeracy test & $4.3 \%$ & $4.2 \%$ \\
\hline Excused from both & $3.9 \%$ & $3.6 \%$ \\
\hline Not excused and test written but no reading score & $3.0 \%$ & $2.3 \%$ \\
\hline Not excused and test written but no numeracy score & $2.6 \%$ & $2.9 \%$ \\
\hline$\%$ of aboriginal students & $8.5 \%$ & $8.5 \%$ \\
\hline$\%$ of special need students & $6.6 \%$ & $8.0 \%$ \\
\hline$\%$ of gifted students & $1.4 \%$ & $2.4 \%$ \\
\hline$\%$ of students in French Immersion programs & $5.5 \%$ & $6.1 \%$ \\
\hline$\%$ of students reporting non-English home language & $21 \%$ & $22.4 \%$ \\
\hline$\%$ Chinese home language & $6.7 \%$ & $8.2 \%$ \\
\hline$\%$ Punjabi home language & $4.5 \%$ & $3.6 \%$ \\
\hline$\%$ other home language & $9.7 \%$ & $10.6 \%$ \\
\hline$\%$ English as a second language (ESL) & $15 \%$ & $7.0 \%$ \\
\hline Average family income (in $2000 \mathrm{C} \$$ ) & $C \$ 66034$ & $C \$ 67015$ \\
\hline Average percentage of incidence of low income & $15.1 \%$ & $15.2 \%$ \\
\hline \multicolumn{3}{|l|}{ Average proportion of parents with education: } \\
\hline Without high school & $14 \%$ & $14 \%$ \\
\hline With high school & $14 \%$ & $14.3 \%$ \\
\hline With bachelor or higher & $12.6 \%$ & $13.2 \%$ \\
\hline
\end{tabular}

16 This restriction excludes $0.8 \%$ of the total number of observations. 
$84 \%$ and $16 \%$, respectively. Average grade-level enrollment among schools offering grade 4 is 41 , and 50 for grade 7 . The proportion of aboriginal students in our final sample is $8.5 \%$ in both grade 4 and grade 7 . The proportion of students who report a language other than English as their home language is $21 \%$ in grade 4 and $22.4 \%$ in grade 7 . Other socioeconomic characteristics obtained from the census such as neighborhood-level average family income, incidence of low income and education seem to be very similar between grade 4 and grade 7 students.

\section{Volatility in School Mean Test Scores}

We begin with a descriptive analysis of variability in school-average test scores. Then, using a simple statistical model built on the work of Kane and Staiger (2002a), we decompose the variation in school-average test scores into two different components: the variation that is due to sampling variation and the variation that is due to other nonpersistent factors.

Figures 1 and 2 portray the distribution of regression-adjusted average grade 4 and grade 7 reading and numeracy test scores by grade enrollment between 1999 and 2006. ${ }^{17}$ It is immediately apparent that there is more variation in average test scores among small schools than big schools, while there does not seem to be a significant difference in average performance by school size. Moreover, Figures 3 and 4 suggest that small schools also experience more yearto-year fluctuation in their grade 4 and grade 7 average test scores compared to

17 Regression-adjusted average test scores are the estimated vector of school-specific intercepts $(\hat{\boldsymbol{b}})$ in the regression $y_{i j}=b_{j}+X_{i j}^{\prime} \beta+\varepsilon_{i j}$, where $X_{i j}$ is the vector of observable socioeconomic status variables (indicators for sex, aboriginal status, ESL status, whether the student is French Immersion, special need status, three categories of home language (Chinese, Punjabi, and English), neighborhood-level average family income, incidence of low income, proportion of total immigrants, proportion of parents without high school degree, with high school degree and with bachelor's degree or higher). Since there might be systematic differences across schools of different size in student characteristics, the Regression-adjusted average test scores account for these differences and allow us to get a better picture of the variation induced by sampling variation by grade size. Although not presented here, simple school average test scores also exhibit the same patterns. It should be mentioned that regression-adjusted school test scores are only used to produce these graphs. Following Kane and Staiger (2002a), the rest of the analysis is done using simple school average test scores. Results reported by Kane and Staiger (2001), however, suggest that using regression-adjusted school average test scores generate similar results. 

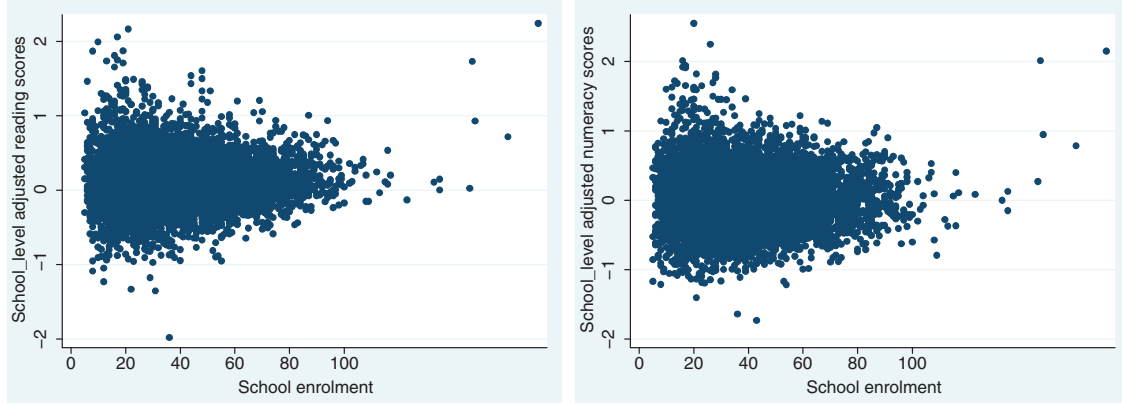

Figure 1: Grade 4 Adjusted Reading and Numeracy Average Test Scores by enrollment level (1999-2006).
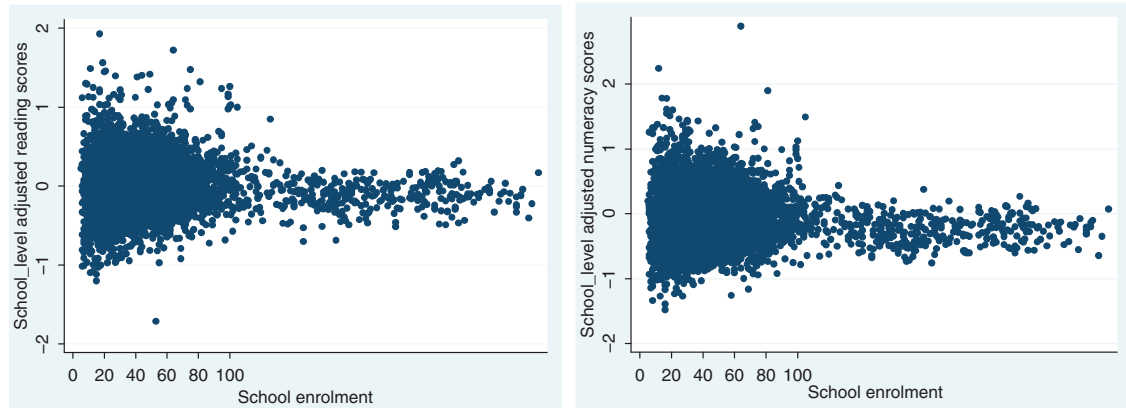

Figure 2: Grade 7 Adjusted Reading and Numeracy Average Test Scores by enrollment level (1999-2006).
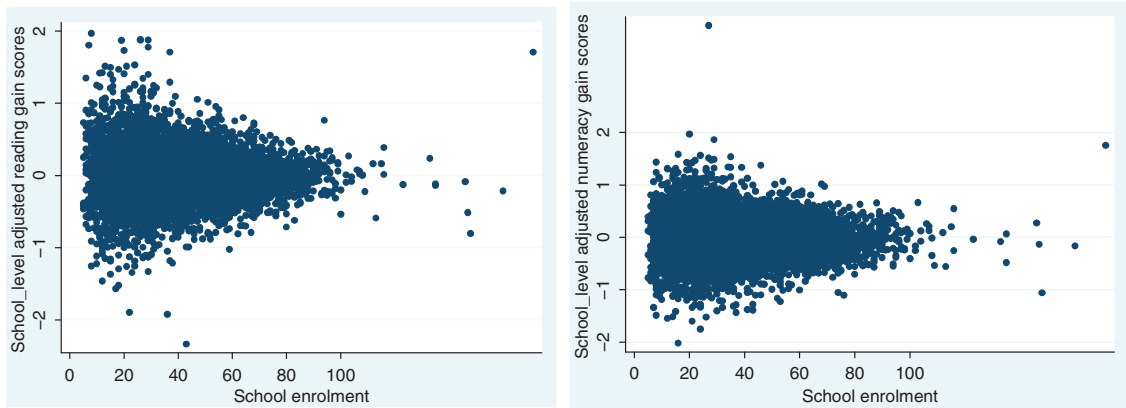

Figure 3: Grade 4 Adjusted Reading and Numeracy Gains by enrollment level (1999-2006). 

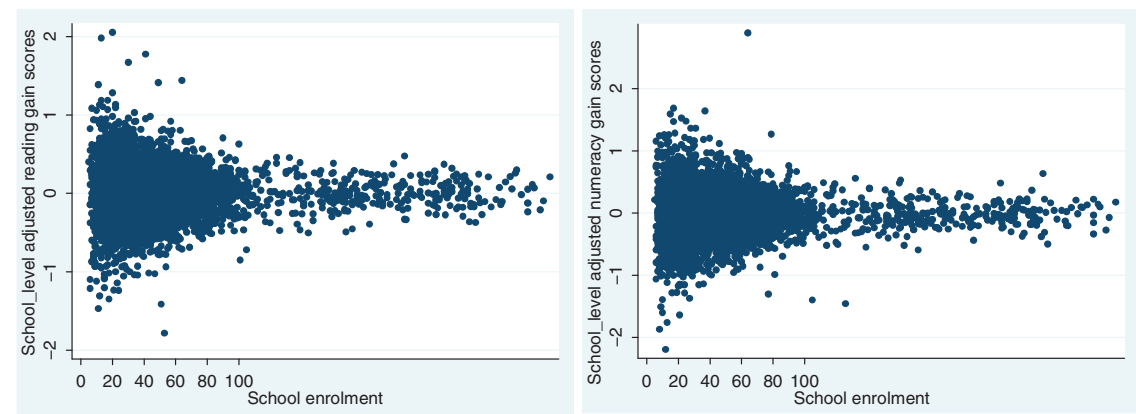

Figure 4: Grade 7 Adjusted Reading and Numeracy Gains by enrollment level (1999-2006).

big schools. ${ }^{18}$ The most likely cause is sampling variation, since its magnitude is a decreasing function of school size. We return to this hypothesis below.

Tables 2 and 3 further illustrate transitory year-to-year variation in grade 4 and grade 7 average test scores. If mean test scores are strongly influenced by transitory factors, a ranking based on these scores will be similar to a ranking based on a pure lottery. The upper panel of each table uses FSA reading scores and the lower panel uses FSA numeracy scores to compare school rankings under different scenarios.

Column 1 illustrates the case where school-average test scores are completely stable over time. Under this scenario, $20 \%$ of schools will always appear in the top $20 \%$ of the distribution of school-average test scores, and $80 \%$ of schools will never appear in the top $20 \%{ }^{19}$ In contrast, column 2 illustrates the case where schools are assigned to different percentiles based on a pure lottery: all schools have an independent $20 \%$ probability of appearing in the top $20 \%$ of the distribution of school-average test scores in each year. Under this scenario, we expect nearly $17 \%$ of schools to never appear in the top $20 \%$, only $0.1 \%$ appear in the top $20 \% 6$ times out of 8 , and none to appear in the top $20 \%$ in all 8 years.

Column 3 ranks schools based on their actual school-average FSA scores. The data lie somewhere between the two extremes of complete stability and a lottery. Looking at grade 4 results, $46 \%$ of schools never appear in the top $20 \%$ of average FSA reading scores and 2.2\% appear in the top 20\% for all 8 years;

18 This suggests that higher variation in average test score levels among smaller schools that is evident in Figures 1 and 2 is not solely due to larger heterogeneity among them.

19 It is clear that total stability of schools' performance will never happen under any useful school achievement measure, but it will allow us to lay out a framework with two extreme scenarios to explore the extent to which different test-based rankings resemble a lottery. 


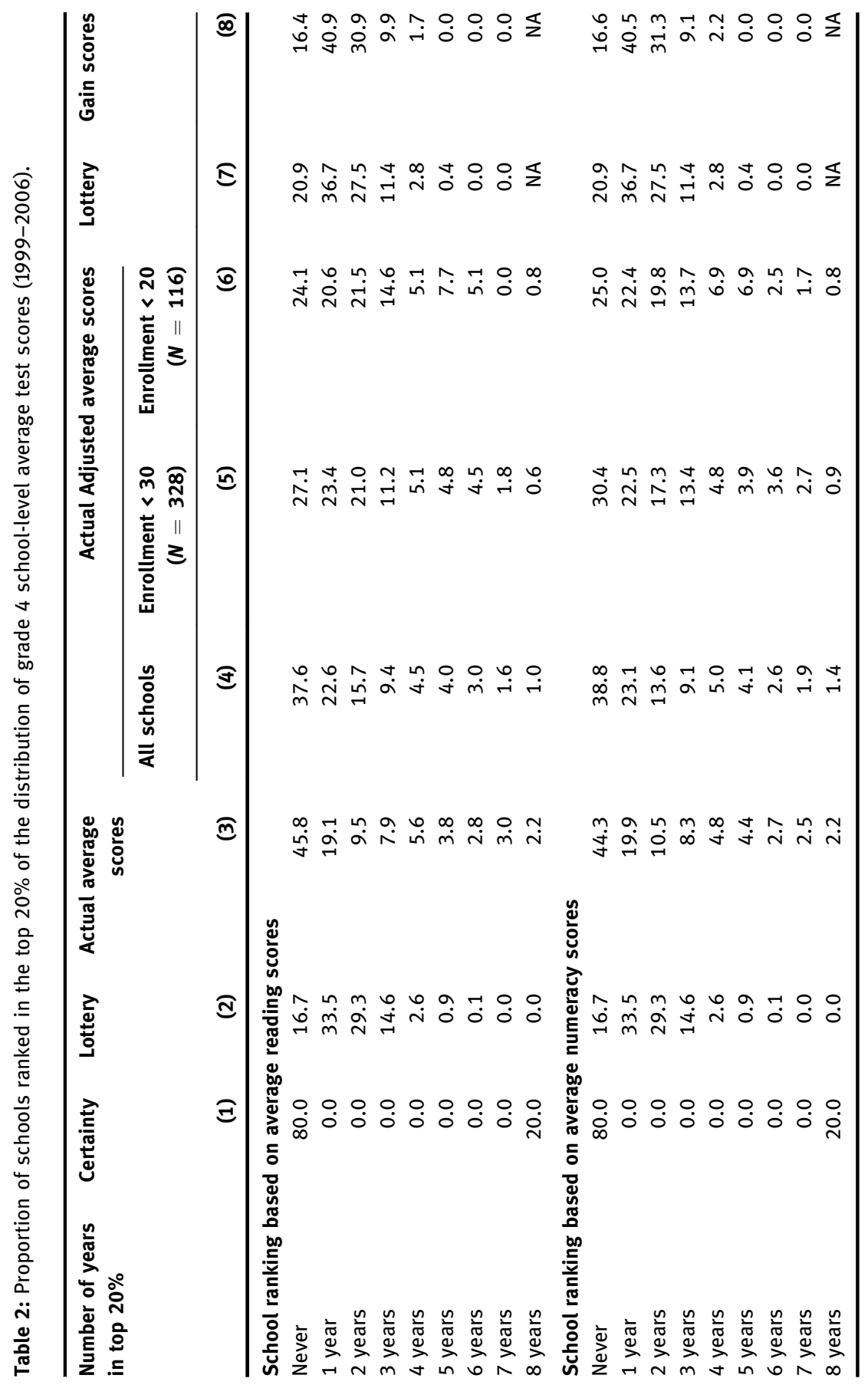




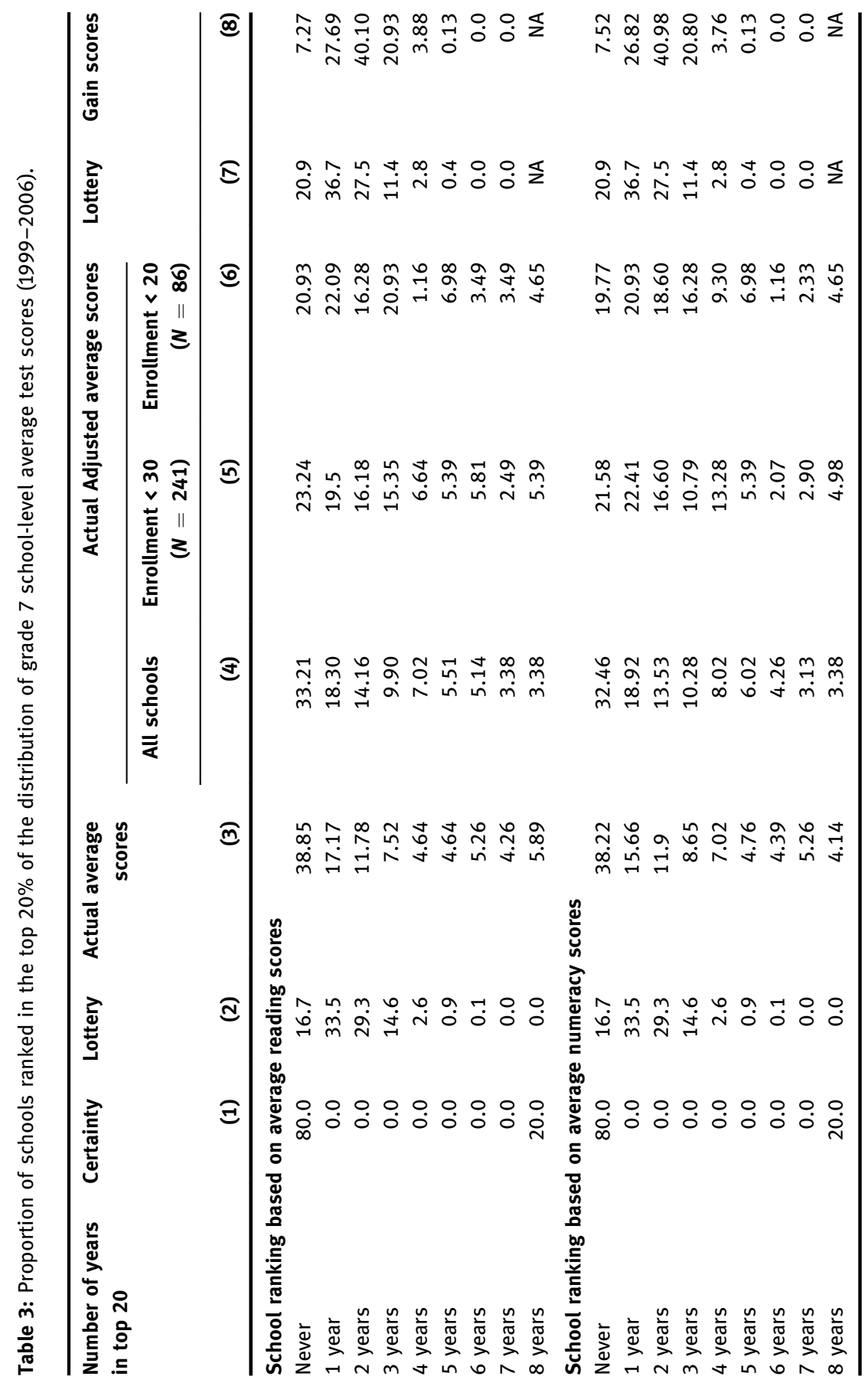


these numbers are $39 \%$ and $6 \%$ for grade 7 , respectively. The results are almost identical for numeracy scores. However, one should bear in mind that part of the stability in ranking based on simple FSA levels may reflect the unchanging characteristics of the student populations feeding the schools and not necessarily due to persistent educational practices in the schools. Controlling for students' observable characteristics, columns 4 results more closely resemble a lottery. Columns 5 and 6 also control for students' observable characteristics, but restrict the sample to schools with enrollment less than 30 and 20 students, respectively. The results suggest that among smaller schools, the volatility in schools-average test scores is even more similar to a lottery. The most likely cause is sampling variation, whose magnitude decreases with sample size.

Finally, as column 8 illustrates, school gain scores (the change in schoolaverage test score from 1 year to the next) are even more volatile than score levels, and consequently rankings based on gain scores are even more similar to a lottery. ${ }^{20}$ This is potentially partly due to the fact that gain scores are based on differences in test scores over 2 consecutive years, which magnifies the effect of nonpersistent factors on variation in schools' test scores and removes any permanent components.

\subsection{Sampling Variation}

We can think of successive cohorts of students entering a school over time as random samples drawn from a local population feeding that school. Therefore, even if the feeding population does not change, school-average test scores will vary from year to year due to random variation in the sample of students, or sampling variation. Given the relatively small number of students in an average school (41 in grade 4 and 50 in grade 7 in our data), and given the fact that only $10-15 \%$ of the variation in students' test scores in our data is between schools, sampling variation can substantially change the position of a school in the distribution of school average test scores.

There are two factors that determine the magnitude of sampling variation: the number of students who write the test in the school, and the heterogeneity of individual test scores in the feeding population. Conditional on all other factors that could influence a school's average test score over time, smaller schools will

20 These results are consistent with Kane and Staiger (2001) finding that gain scores exhibit more volatility due to transitory factors compared to average test scores (levels). 
experience more volatility in their mean test scores due to sampling variation than bigger schools.

In what follows, we use a simple model and apply basic sampling theory to estimate the expected amount of variance in a school's average test score due to sampling variation. ${ }^{21}$ Consider a simple model of test score determination:

$$
Y_{i j t}=\lambda_{j}+\delta_{j t}+\theta_{i}+U_{i j t}
$$

Here, $Y_{i j t}$ denotes student $i$ 's test score at school $j$ in year $t, \lambda_{j}$ is the school-level time-invariant component of a student's score, $\delta_{j t}$ is the school-level time-varying component (decomposed below into a persistent component and a transitory component), $\theta_{i}$ is student-level time-invariant component (representing testtaking ability or smartness, socioeconomic characteristics, and other factors), and $U_{i j t}$ is a student-level transitory shock.

Assumption 1: Transitory shocks are idiosyncratic: $U_{i j t} \sim \operatorname{iid}\left(0, \sigma_{u}^{2}\right)$.

Assumption 2: Different cohorts of students entering a school in a given year are random samples drawn from a population feeding that school, so that $\theta_{i} \sim \operatorname{iid}\left(\mu_{\theta}, \sigma_{\theta}^{2}\right)$ for the feeding population. ${ }^{22}$

Given eq. [9], the average test score for a given school $j$ in year $t$ has the form

$$
\bar{Y}_{j t}=\Sigma_{i \in A_{j}} \frac{Y_{i j t}}{N_{j t}}=\lambda_{j}+\delta_{j t}+\Sigma_{i \in A_{j}} \frac{1}{N_{j t}} \theta_{i t}+\Sigma_{i \in A_{j}} \frac{1}{N_{j t}} U_{i j t} .
$$

where $N_{j t}$ is enrollment level at school $j$ at time $t$. The cross-sectional variance in average test scores over all schools in a given year is

$$
\begin{aligned}
\operatorname{Var}\left(\bar{Y}_{j t} \mid t\right) & =\operatorname{Var}\left(\lambda_{j}\right)+\operatorname{Var}\left(\delta_{j t} \mid t\right)+\operatorname{Var}\left(\bar{\theta}_{i(t)} \mid t\right)+\operatorname{Var}\left(\bar{U}_{i j t} \mid t\right) \\
& =\sigma_{\lambda}^{2}+\sigma_{\delta}^{2}+\left[\sigma_{\theta}^{2}+\sigma_{U}^{2}\right] E\left(\frac{1}{N_{j t}}\right) .
\end{aligned}
$$

Defining $\varepsilon_{i j t}=\theta_{i}+U_{i j t}$, we can rewrite eq. [9] as

$$
Y_{i j t}=\lambda_{j}+\delta_{j t}+\varepsilon_{i j t} .
$$

21 The model formalizes the method used by Kane and Staiger (2002a) to calculate the sampling variation. This formalized model helps to understand how we can separately measure the effect of sampling variation and other transitory factors, and better illuminates the underlying assumptions behind these calculations.

22 The feeding population can be the same for multiple schools in the same neighborhood, or it could be different. 
An unbiased estimator of the within-school variance of individual test scores at a given school is

$$
\begin{aligned}
\left.\operatorname{Var} \widehat{\left(y_{i j t} \mid\right.}, t\right) & =S_{j t}^{2}=\frac{1}{N_{j t}-1} \sum_{i=1}^{N_{j}}\left(y_{i j t}-\bar{y}_{j t}\right)^{2} \\
& =\frac{1}{N_{j t}-1} \sum_{i \in A_{j}}\left(\varepsilon_{i j t}-\bar{\varepsilon}_{j t}\right)^{2}=S_{\varepsilon}^{2}=S_{\theta}^{2}+S_{U}^{2}
\end{aligned}
$$

As eq. [13] suggests, the source of variation in student test scores within a given school is either due to differences in students' time-invariant characteristics (test-taking ability, socioeconomic background, etc.), $S_{\theta}^{2}$, or due to idiosyncratic shocks affecting a student performance in the exam (all factors that could cause "random variation in health, motivation, mental efficiency, concentration, forgetfulness, carelessness, subjectivity or impulsiveness in response and luck in random guessing"23), $S_{U}^{2}$.

Applying sampling theory, the expected variance in school-average test scores due to sampling variation is

$$
\operatorname{Var} \widehat{\left(\bar{y}_{j t} \mid j, t\right)}=\frac{S_{j t}^{2}}{N_{j t}}=\frac{1}{N_{j t}}\left(S_{\theta}^{2}+S_{U}^{2}\right) .
$$

Given Assumptions 1 and 2, $S_{\theta}^{2}$ and $S_{U}^{2}$ are unbiased estimates of $\sigma_{\theta}^{2}$ and $\sigma_{u}^{2}$. Therefore, the higher is the variance induced by student-level transitory shocks $\left(\sigma_{u}^{2}\right)$, and the higher are differences in students' time-invariant characteristics $\left(\sigma_{\theta}^{2}\right)$ in the population feeding a given school, the larger will be the variance induced by year-to-year variation in the composition of students (i.e. sampling variation). On the other hand, the larger number of students within a given school in a given year $\left(N_{j t}\right)$ lowers the effect of sampling variation. This is driven by the fact that averaging over a larger number of students dampens the noise created by sampling variation.

Averaging eq. [14] over all schools gives the expected variance in mean test scores due to sampling variation for an average school:

$$
\frac{\sum_{j=1}^{J} \widehat{\operatorname{Var}}\left(\bar{y}_{j t} \mid j, t\right)}{J}=\left[S_{\theta}^{2}+S_{U}^{2}\right]\left[\left(\Sigma_{j=1}^{J}\left(\frac{1}{N_{j t}}\right)\right) / J\right]
$$

Note this is an unbiased estimator of the last component in eq. [11].

The average within-school variance of FSA reading and numeracy scores is 0.88 and 0.83 , respectively, for both grade 4 and grade 7 . Since the overall

23 See Feldt and Brennan (1989). 
variance of individual FSA reading and numeracy scores is normalized to one for each grade, this implies that within the average school, heterogeneity in students' test scores is nearly as large as in the overall population. In other words, on average, the test scores of two students drawn randomly from a given school are likely to differ nearly as much as two students drawn from the population of BC students at large. ${ }^{24}$

The estimated expected variance in mean FSA reading and numeracy scores for an average school due to sampling variation, from eq. [15], is 0.028 (reading) and 0.025 (numeracy) for grade 4, and 0.026 (reading) and 0.024 (numeracy) for grade $7 .{ }^{25}$ If we focus on schools of average size by looking only at the two middle quartiles of enrollment by grade, the overall cross-sectional variance of school-average FSA reading and numeracy scores is 0.13 and 0.17 , respectively, for grade 4; and 0.13 and 0.19 , respectively, for grade 7 . It follows that for these average-sized schools, $21.5 \%$ and $14.7 \%$ of the total variation in fourth-grade mean FSA reading and numeracy scores, respectively, is due to sampling variation. For grade 7 , the figures are $20 \%$ and $12.6 \%$, respectively. ${ }^{26}$

In order to gain a better understanding of the importance of sampling variation, we calculate the 95\% confidence interval for an average school's mean test score using the estimated expected variance due to sampling variation:

$$
\begin{gathered}
\mathrm{Cl}_{95}^{\text {Grade4_Reading }}=\bar{Y}_{\mathrm{Re}}^{\mathrm{G} 4} \pm 1.96\left(\sqrt{E_{j}\left[\widehat{\left.\operatorname{Var}\left(\bar{Y}_{j}\right)\right]}\right.}\right)=[-0.35,0.34] \\
\mathrm{Cl}_{95}^{\text {Grade7_Reading }}=\bar{Y}_{\mathrm{Re}}^{\mathrm{G} 7} \pm 1.96\left(\sqrt{E_{j}\left[\widehat{\operatorname{Var}\left(\bar{Y}_{j}\right)}\right]}\right)=[-0.30,0.32]
\end{gathered}
$$

where $\bar{Y}_{\text {Re }}$ is the overall mean of school-average FSA reading scores. The confidence interval extends from roughly the 17th to 84th percentile of the distribution of school-average FSA reading scores for grade 4, and from the 19th to 80th percentile for grade 7 . This implies that for an average grade 4 school in our sample, we cannot rule out with $95 \%$ probability that its average score the following year is as large as the 84th percentile, or as small as the 17th percentile, due to variability induced by sampling variation alone.

24 Using data from North Carolina, Kane and Staiger (2002a) also report similar results.

25 As it is also pointed out by Kane and Staiger (2002a), with any peer effects, the effect of sampling variation will be amplified and these calculations will underestimate the importance of sampling variation.

26 These estimates are similar in magnitude to those reported by Kane and Staiger (2002a) for grade 4 students in North Carolina. 
A more conservative measure is based on the $50 \%$ confidence interval for an average school's mean test score given sampling variation, which measures the degree of variability induced by sampling variation with the probability of a coin toss. This confidence interval extends from the 36th to 63rd percentile of the distribution of school-average reading scores for both grade 4 and grade 7 . This remains a very wide interval.

\subsection{Other Transitory Factors}

Sampling variation is only one of the transitory factors that can affect schoolaverage test scores. There are other transitory shocks that generate nonpersistent changes in schools' mean test scores in addition to sampling variation. Specifically, the school-level time-varying component of student test scores (i.e. $\delta_{j t}$ in eq. [9]) will also induce nonpersistent variation in school-average test scores. Real-world examples include the existence of a few troublemaking students in a class, a dog barking in the playground or construction noise on the day of the exam, a school-wide illness, or special chemistry between a teacher and a cohort of students, etc.

Following Kane and Staiger (2002a) and given the framework developed in Section 4.1, we apply an indirect method to estimate the nonpersistent variation in test scores attributed to these other transitory factors. ${ }^{27}$ First, we estimate the total variation in mean test scores due to all transitory factors by measuring the degree of persistence in change in test scores between two consecutive years. Then we back out the portion due to sampling variation. The remaining component is attributable to other transitory factors.

We first decompose the school-level time-varying effect on student scores in eq. [9] into two components:

$$
\delta_{j t}=v_{j t}+\tau_{j t}
$$

where $v_{j t}$ is the persistent component which is assumed to depend on last year value in addition to a new innovation each year $\left(v_{j t}=v_{j t-1}+\rho_{j t}\right)$, and $\tau_{\mathrm{jt}}$ is the transitory component. The persistent component reflects differences across schools in teacher quality, curriculum, facilities, etc. that persist over time,

27 The adopted method to measure the variation induced by other transitory factors is similar to that of Kane and Staiger (2002a). However, since we start from a student-level test determination model (eq. [9]) to formalize the calculation of sampling variation, as opposed to a schoollevel model used by Kane and Staiger (2002a), the model makes the link between total variance due to transitory factors, sampling variation and other transitory factors clearer. 
and the transitory component reflects differences driven by idiosyncratic shocks at the school-level discussed before.

Assumption 3: $\rho_{j t} \sim \operatorname{iid}\left(0, \sigma_{\rho}^{2}\right)$ and $\tau_{j t} \sim \operatorname{iid}\left(0, \sigma_{\tau}^{2}\right){ }^{28}$

The average test score for a given school $j$ in year $t$ will therefore have the form

$$
\begin{gathered}
\bar{y}_{j t}=\lambda_{j}+v_{j t}+\tau_{j t}+\bar{\theta}_{i(t)}+\bar{U}_{i j t} \\
\Delta \bar{y}_{j t} \equiv \bar{y}_{j t}-\bar{y}_{j t-1}=\rho_{j t}+\tau_{j t}-\tau_{j t-1}+\bar{\theta}_{i(t)}-\bar{\theta}_{i(t-1)}+\bar{U}_{i j t}-\bar{U}_{i j t-1}
\end{gathered}
$$

The correlation between test score gains this year and last year can be written as

$$
\operatorname{Corr}\left(\Delta \bar{y}_{j t}, \Delta \bar{y}_{j t-1}\right)=\frac{\operatorname{Cov}\left(\Delta \bar{y}_{j t}, \Delta \bar{y}_{j t-1}\right)}{\sqrt{\operatorname{Var}\left(\Delta \bar{y}_{j t}\right)} \times \sqrt{\operatorname{Var}\left(\Delta \bar{y}_{j t-1}\right)}}=\frac{-\left\{E_{j}\left(\sigma_{\tau}^{2}\right)+\left[\sigma_{\theta}^{2}+\sigma_{u}^{2}\right] E_{j}\left[\frac{1}{N_{j t}}\right]\right\}}{\operatorname{Var}\left(\Delta \bar{y}_{j t}\right)}
$$

The numerator is the negative of the total variance of all transitory factors and the denominator is the total variance of gain scores $\left(\Delta \bar{y}_{j t}\right)$. Since we can calculate the left-hand side of eq. [19] directly, as well as $\operatorname{Var}\left(\Delta \bar{y}_{j t}\right)$, we can recover the total variance of all transitory factors from their product. Subtracting from this our earlier estimate of the magnitude of sampling variation (from eq. [15]), we can back out the variance of all other transitory factors, $E_{j}\left(\sigma_{\tau}^{2}\right)$.

Tables 4 and 5 summarize the results for different quartiles of grade 4 and grade 7 enrollment for both FSA reading and numeracy scores. The analysis is done separately for different years, while the bottom panel of each table presents the results of the variance decomposition for all years combined. As expected, the estimated sampling variance is bigger for small schools than bigger schools and the magnitudes are stable over time. The estimated variance of other transitory factors however varies over time, which is due to the random nature of the events that generate them.

Overall, the results suggest that school-average FSA reading and numeracy scores are not very reliable measures of persistent differences in school-average achievement, particularly among small schools. Looking at the bottom panel of each table, nearly $47 \%$ of the variance of school-average grade 4 FSA reading scores and $40 \%$ of FSA numeracy scores among schools in the smallest quartile

28 As Kane and Staiger (2002a) point out, the effect of transitory factors on average test scores will be underestimated if $\rho_{j t}$ and $\rho_{j t-1}$ are not independent (for instance, if school $\mathrm{j}$ was consistently improving in a systematic way). Kane and Staiger (2001) propose a method for a more general treatment, however their results stay similar. 


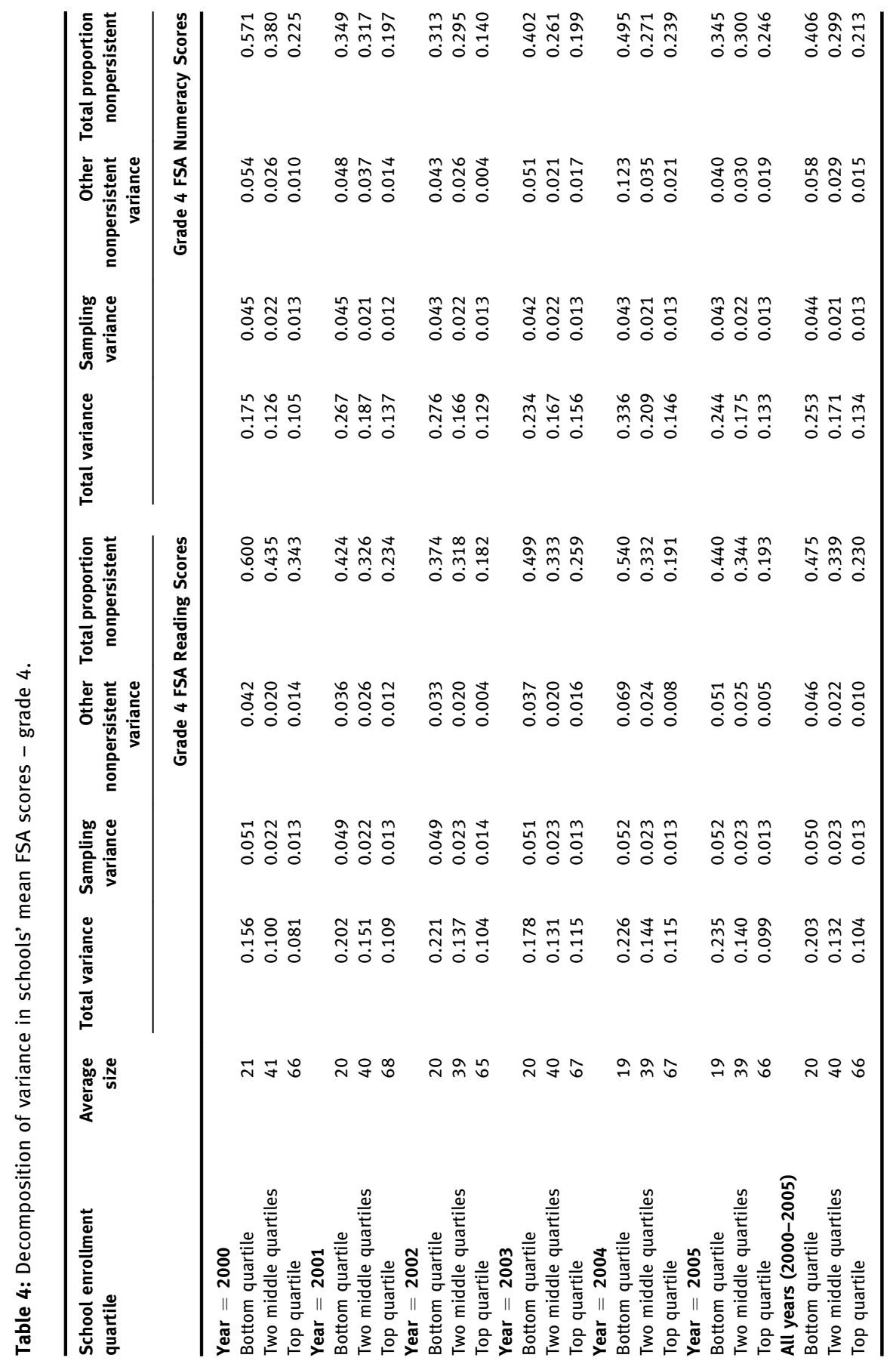




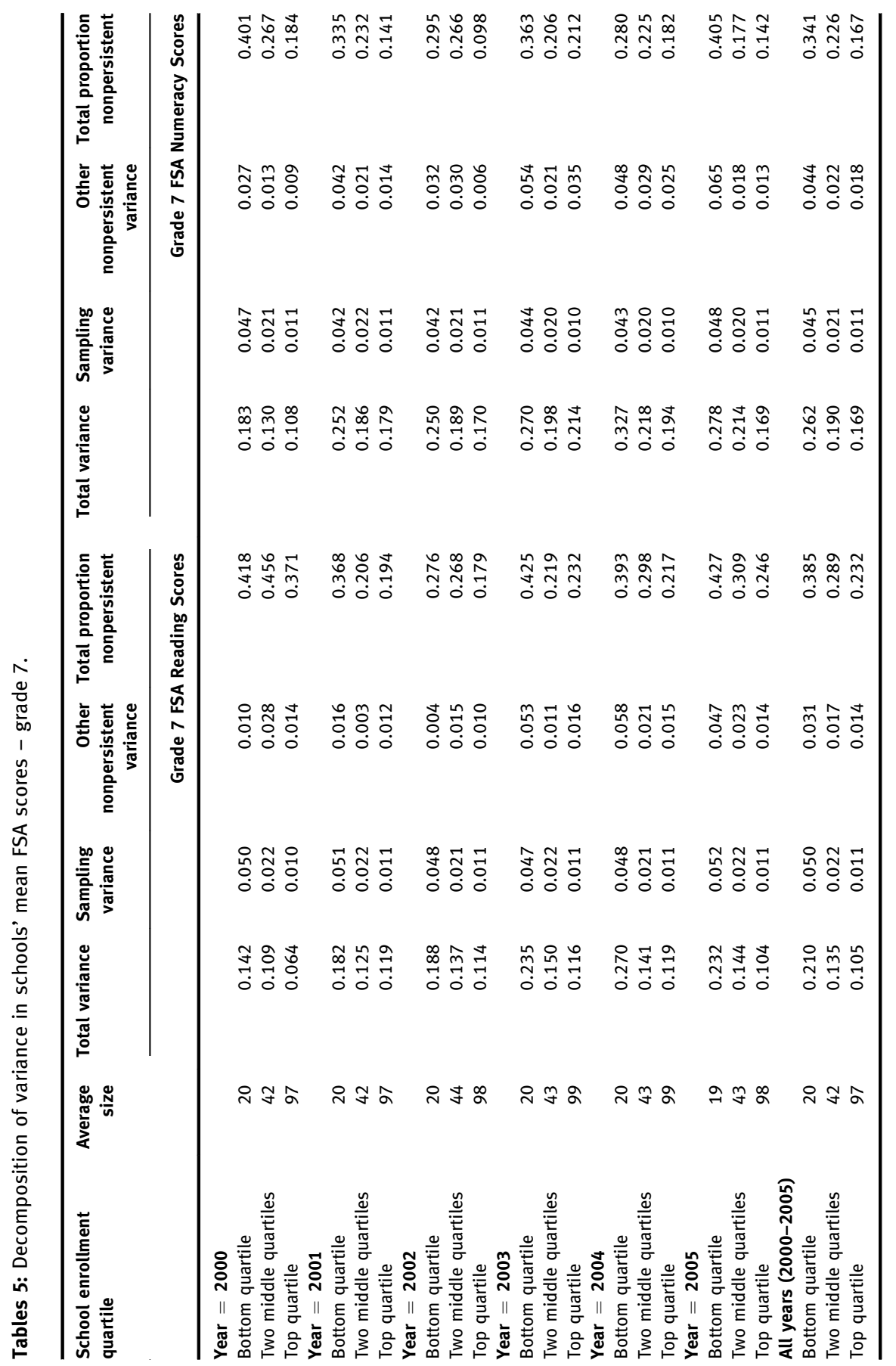


of enrollment size is due to sampling variation and other nonpersistent factors. For grade 7 the estimates are 38\% and 34\%, respectively. As expected, transitory factors account for a smaller share of the cross-sectional variance among larger schools. For the two middle quartiles, $33 \%$ and $29 \%$ of the cross-sectional variance in grade 4 and grade 7 average FSA reading scores is due to nonpersistent factors respectively. The corresponding numbers are 30\% and $23 \%$ for numeracy scores. For schools in the largest quartile, $23 \%$ of the variance across schools in grade 4 and grade 7 average FSA reading scores is due to transient factors, while for numeracy scores these numbers are $21 \%$ and $17 \%$ for grade 4 and grade 7 , respectively. It also worth mentioning that almost across the board, the amount of imprecision in average FSA numeracy scores due to nonpersistent factors is smaller than average FSA reading scores. ${ }^{29}$

One interesting question that could arise from these results is whether schools could become large enough so their test scores provide reasonable information about their performance? We cannot extrapolate outside our data range to predict the school size at which test-based school achievement measures will provide a reliable signal of school quality. This is because as schools become larger, the cross-sectional variance across schools will also change. For instance, as our Tables 4 and 5 suggest, total variance in test scores across schools becomes smaller across the board as we move to higher enrollment quartiles. This highlights the fact raised by Kane and Staiger (2001) that "it is not the absolute amount of imprecision that matters, but the amount of imprecision relative to the underlying signal that dictates the reliability of any particular measure." ${ }^{30}$ In addition, it is not obvious how the variation induced by other non-persistent factors is going to change, given their random nature, as schools become larger.

However, despite the aforementioned limitations, we can examine the effect of transitory factors for larger schools by pooling student-level observations across years for each school. We can also pool these observations across grades to create even larger schools. Doing so will also provide some insights into the

29 This result is consistent with Kane and Staiger (2001). They argue that this is due to less signal variation in reading scores.

30 Moreover, as Kane and Staiger (2001) point out, while sampling variation is a bigger problem for smaller schools, there is more heterogeneity in school size among larger schools versus smaller schools. Therefore, while the amount of variation due to sampling variation is larger for smaller schools versus larger schools, at the same time because smaller schools are more uniform in size, the probability of having a very high or very low average test score due to sampling variation for smaller schools is more similar than larger schools. Larger schools will have a greater heterogeneity in the probability of experiencing a very high or very low average test score due to sampling variation. 
extent to which pooling test scores across grades and years will reduce the imprecision in these measures. In order to be able to implement the variance decomposition results similar to those reported in Tables 4 and 5, we need at least 3 years of observation for each school. This is because in order to calculate the contribution of other non-persistent factors we need to estimate the correlation between the changes in test scores in two consecutive years (as described in eq. [19]).Therefore, given that we have 8 years of data for each school, we use the most recent 6 years and pool observations for each school grade over three 2-year time periods: 2001-2002, 2003-2004, and 2005-2006. Additionally, we also pool observations for each school both across grades and across these 2-year time periods. This results in even larger school sizes.

The results of variance decomposition for these larger schools are reported in Table 6. First of all, pooling observations across grades and years gives us substantially larger schools. The four largest quartiles have average school sizes of 131, 161, 197, and 269. Consistent with results reported in Tables 4 and 5, the contribution of sampling variation becomes smaller as we move to higher quartiles. However, more careful inspection of the relationship between school size and sampling variance suggests that sampling variance decreases at a decreasing rate as school size increases. Figures 5 and 6 illustrate the relationship between school size and the magnitude of sampling variance for reading and numeracy scores, respectively, using all the estimates reported in Tables 4-6. While the sampling variance drops quickly for smaller schools as the school size increases, it does not change significantly at higher levels of school size. Figures 7 and 8 suggest a similar relationship between school size and the proportion of total cross-sectional variance across schools due to sampling variation. As expected, the magnitude of other transitory factors does not follow the same pattern given their random nature. For example, looking at the bottom panel of Table 6, it decreases as we move from the bottom to the two-middle quartiles, but then increases as we move to the top quartile.

Nearly $22(21) \%$ of variance in school-average FSA reading (numeracy) scores among schools in the fourth largest quartile in terms of average school size (with an average school size of 131) is due to sampling variation and other transitory factors. For the third largest quartile (with an average school size of 161), these estimates are $8.6 \%$ and $7.2 \%$. However, as we move to the second largest quartile (with an average school size of 197), the contribution of nonpersistent factors becomes larger, $10.3 \%$ and $10.6 \%$ for reading and numeracy scores, respectively. Finally, as we move to the largest quartile (with an average school size of 269), while the contribution of non-persistent factors does not changes for numeracy scores, it becomes even larger for reading scores at $12.1 \%$. We observe the same patterns across other quartiles in the table. 


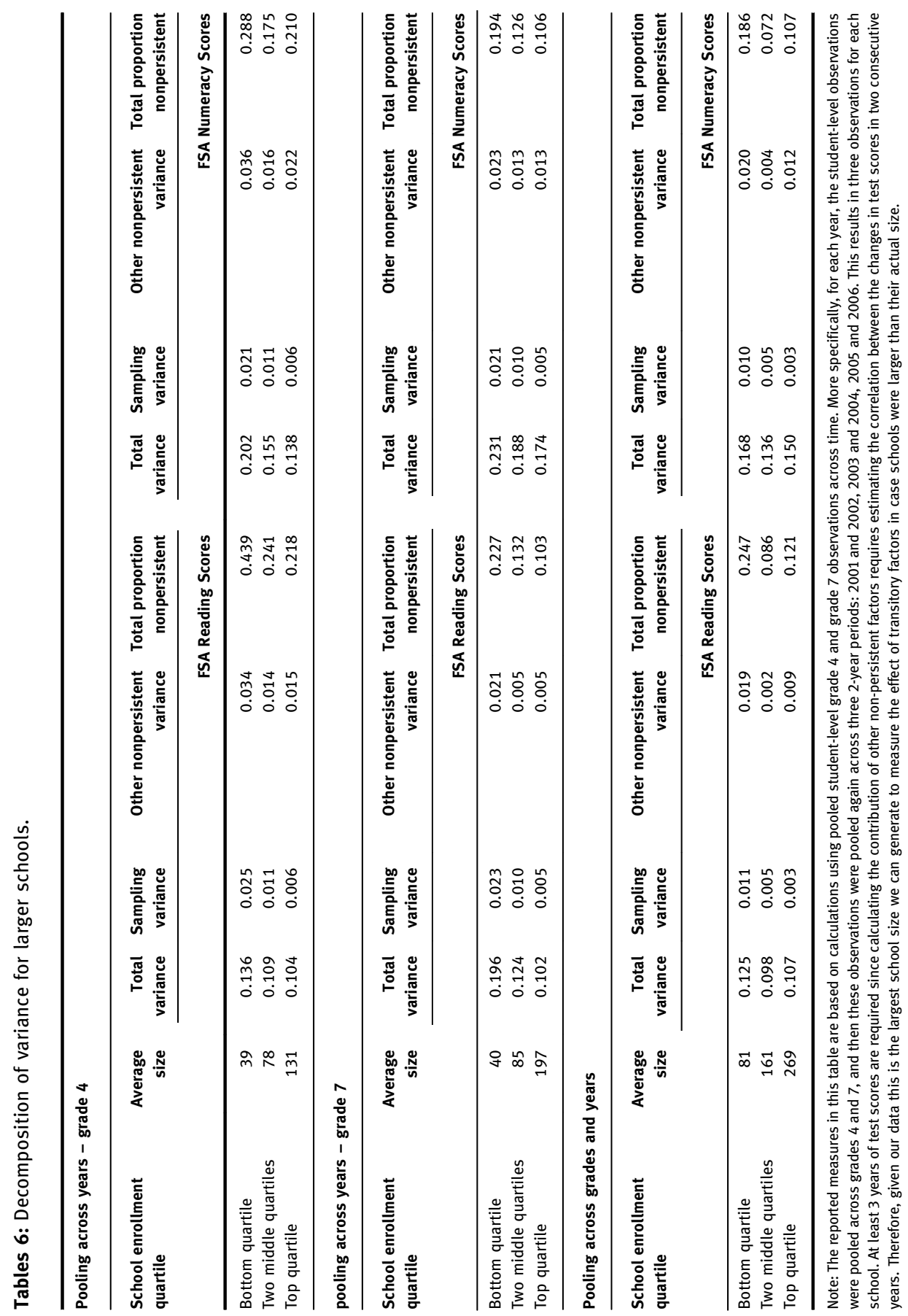


These results highlight two important issues. First, due to the decreasing effect of larger school size on reduction in sampling variation (illustrated in Figures 5-8), changes in cross-sectional variance across school as we move across quartiles, and random changes in the contribution of other transitory factors that are not a monotonic function of changes in school size, it is not

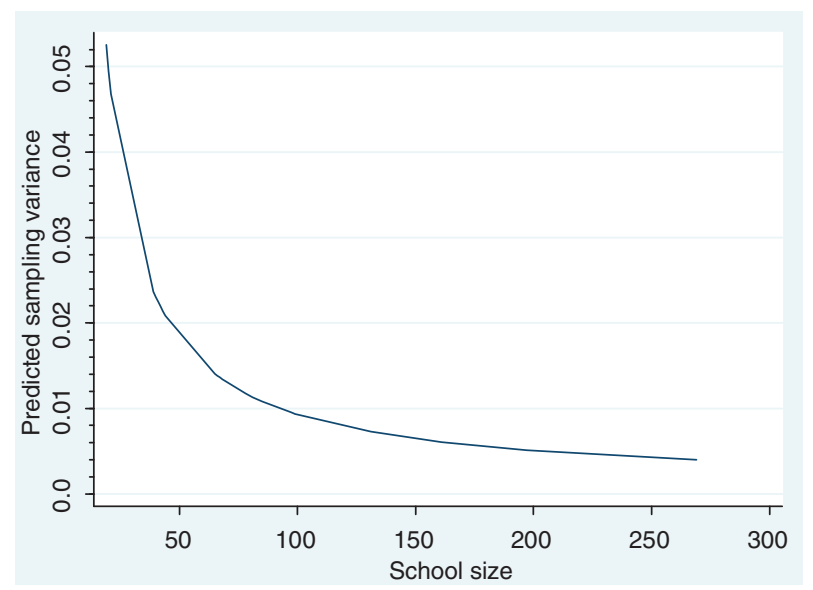

Figure 5: Relationship between school size and sampling variance (reading scores), Fractional polynomial fitted plot.

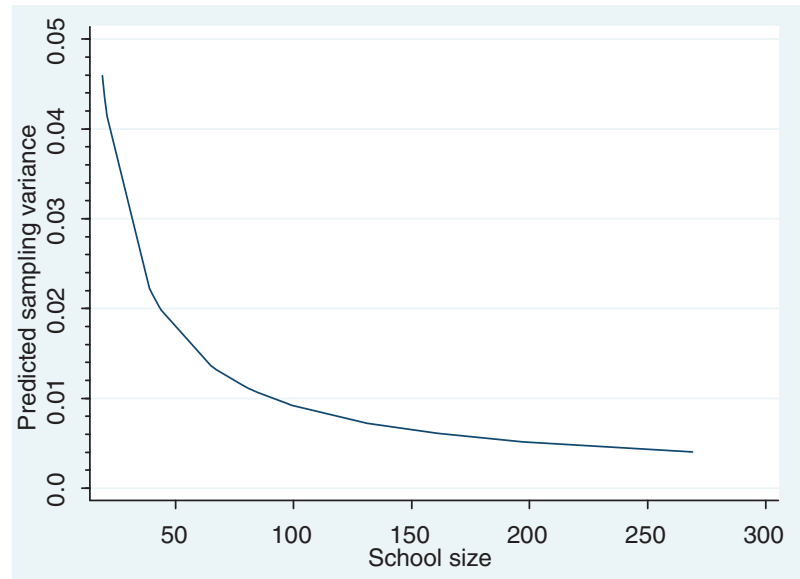

Figure 6: Relationship between school size and proportion of total cross-sectional variance due to sampling variance (reading scores), Fractional polynomial fitted plot. 


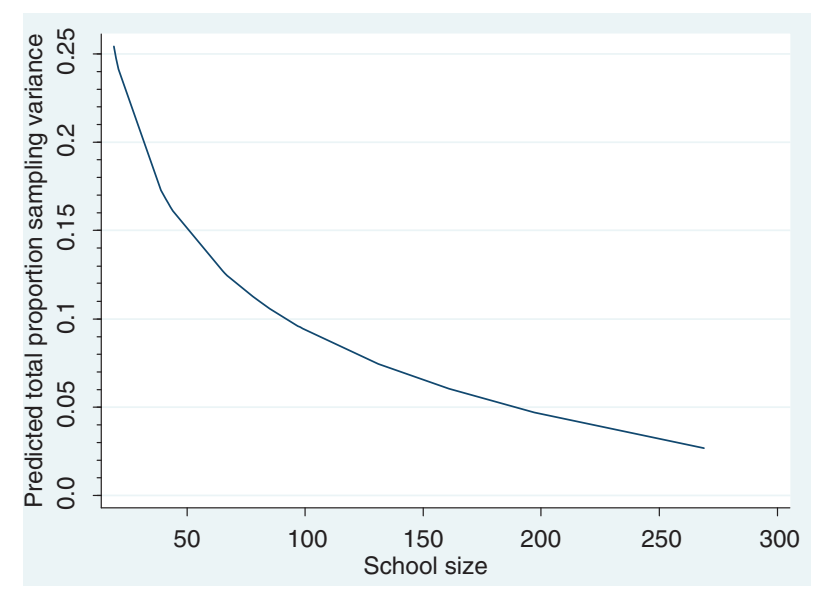

Figure 7: Relationship between school size and sampling variance (numeracy scores), Fractional polynomial fitted plot.

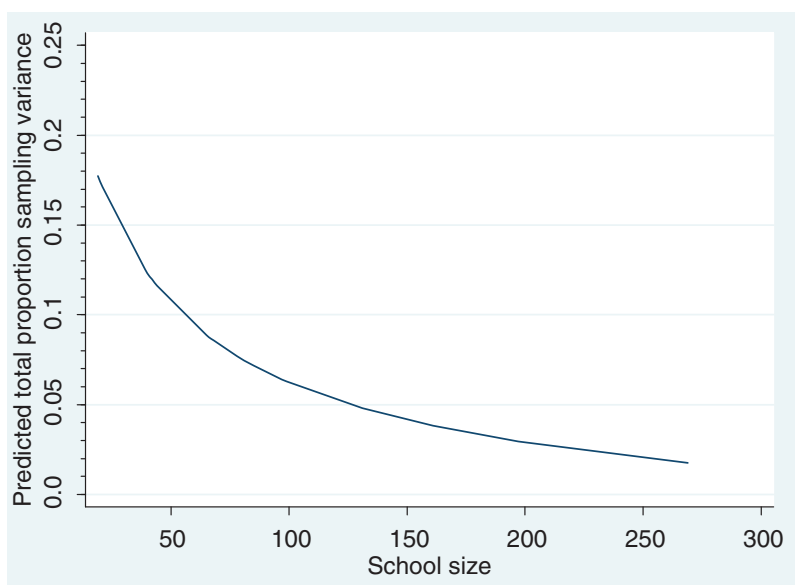

Figure 8: Relationship between school size and proportion of total cross-sectional variance due to sampling variance (numeracy scores), Fractional polynomial fitted plot.

obvious whether the effect of total transitory factors becomes smaller as the schools become substantially larger. Second, total transitory factors can still have a considerable impact on test-based school achievement measures for substantially large schools. For instance, comparing our results in the bottom panel of Table 5 with our results in bottom panel of Table 6, while the average school size has increased by $1,245 \%$ (from $20 \%$ to $269 \%$ ), the contribution of 
Table 7: The Fraser Institute annual scores variance decomposition.

\begin{tabular}{lrrr}
\hline Year & Total variance & $\begin{array}{c}\text { Total variation due to } \\
\text { nonpersistent factors }\end{array}$ & Total proportion nonpersistent \\
\hline 2001 & 3.010 & 0.676 & 0.224 \\
2002 & 2.987 & 0.665 & 0.222 \\
2003 & 3.182 & 0.750 & 0.235 \\
2004 & 3.244 & 0.587 & 0.181 \\
\hline
\end{tabular}

Note: These calculations use the Fraser Institute scores based on 1999/2000, 2000/2001, 2001/2002, 2002/2003, 2003/2004, and 2004/2005 FSA test scores. We limit the sample of schools to those with valid scores in all 6 years. The total number of schools used in the calculations (both public and private) is 711 .

transitory factors only drops by $68 \%$ (from $38 \%$ to $12 \%$ ). The $12 \%$ variation in test scores among the largest schools in our sample, driven by total transitory factors, is still considerably large. To put it into perspective, if we create a $95 \%$ confidence interval for the average school in this quartile using the estimated total expected variance induced by transitory factors, it will extend from 25th to 75th percentile of the average test score distribution. ${ }^{31}$

As it was mentioned before, we also measure the proportion of crosssectional variance in the Fraser Institute school-level scores that is due to all transitory factors (sampling variation and other transitory factors). Friesen et al. (2012) find that public release of these scores has a substantial impact on parents' school choice decisions. Moreover, since the Fraser Institute scores are constructed combining 10 different indicators (see footnote 12), it would be interesting to investigate the extent to which these more sophisticated measures of school performance are influenced by transitory factors. Results are summarized in Table 7and suggest that these scores are also strongly influenced by transitory factors. Between $18 \%$ and $22.4 \%$ of the cross-sectional variance in the Fraser Institute scores are due to transitory factors.

\section{Conclusion}

Sampling variation and one-time mean-reverting shocks are a significant source of observed variation in schools' average test scores. This is of critical

31 This is consistent with the finding of Kane and Staiger (2002a) that a 14-15\% variation in test scores induced by sampling variation will generate a confidence interval that would extend from roughly 25 th to the 75 th percentile. 
importance because there is growing evidence that suggests providing information about school-level achievement has real effects on parents' school choice decisions. More importantly, the results of Friesen et al. (2012), which exploits a very similar sample of schools and students, suggest that some parents' school choice decisions respond to publicly disseminated information about school average test scores soon after it becomes available, and continue to respond to subsequent releases in the following years. This raises even more concerns regarding the noisiness of test-based school achievement measures that are publicly disseminated to parents and are perceived by some as a signal of school performance.

Since school choice decisions are inherently costly, and since there is considerable amount of evidence that suggests these mobility decisions do not necessarily provide academic benefits to students, to the extent they are shaped by imprecise or noisy measures of school performance, they could potentially impose a net cost on parents and students and make them significantly worse off. Moreover, if it becomes apparent to parents that these measures are very noisy and fluctuate significantly from 1 year to the next, they might stop paying attention to new information about school-level achievement, undermining the effectiveness of school choice policies that partly hinges upon the ability to distinguish high-achieving schools from low-achieving schools. In addition, to the extent these noisy test-based school achievement measures are used as one of the factors to identify best educational practices, they could generate a lot of confusion over advantages and disadvantages of different strategies of school reform, and could mislead policy makers and educational authorities into decisions that are costly. Finally, to the extent noisy and imprecise test-based school achievement measures are used in jurisdictions with school accountability systems to evaluate schools' performance, policy makers and educational authorities could be misled into assigning rewards or sanctions to schools based on factors that are outside their control and therefore undermine the effectiveness of these accountability systems. Chay, McEwan, and Urquiola (2005) provide strong evidence that suggests policy evaluations based on such noisy measures of school effectiveness have the potential to be misleading.

Nonpersistent factors are found to induce greater year-to-year variation in average test scores of small schools than bigger schools. However, even bigger schools still experience a significant volatility in their average test scores due to transitory factors. This suggests that combining test scores from more than one grade, or from more than 1 year, to increase the sample size and dampen the transitory volatility, will not resolve the concerns regarding the reliability of 
these test-based school achievement measures. ${ }^{32}$ Our results suggest that due to the decreasing effect of larger school size on reduction in sampling variation, and changes in between-school variance and the effect of other transitory factors, total transitory factors still have a considerable impact on testbased school achievement measures even after pooling test scores across grades and years, and could therefore move a school significantly in the distribution of scores. Therefore, it is not clear whether consulting several years of results, for example, as suggested by the Fraser Institute, will provide meaningful information to parents. As the previous discussion of results in Tables 2 and 3 suggests, the changes in the position of schools, particularly small schools, in the distribution of test scores over several years, is not far from a lottery process. ${ }^{33}$ To the extent these test-based measures are used by parents to inform their school choice decisions, this is likely to only add more confusion to parents' decision-making regarding school choice, and might mislead them in this process into making costly decisions with no academic benefits for their children.

Our results also suggest that significant changes in average test scores of larger schools should be treated as a stronger signal about persistent changes in performance compared to small schools. This is something that is not directly reflected in the constructed scores by the Fraser Institute, and again could mislead or confuse some parents. This also highlights the importance of communicating the statistical properties of these measures, especially when they are publicly disseminated. To the extent these measures are used to identify best practices in education, failure to do so might send confusing signals to parents and schools and could make it difficult to identify the areas of academic performance in which improvement can be made. These results should also warn educational authorities against naïve policies or interventions that attach monetary/nonmonetary rewards or sanctions to schools based on noisy measures of school performance. As a growing literature attests, designing meaningful measures of school effectiveness continues to be a

32 This is also apparent from the examination of the Fraser Institute scores. Despite the fact that they are more sophisticated measures constructed using 10 different indicators (including pooling grade 4 and grade 7 reading, writing and numeracy scores together), they are still strongly influenced by transitory factors.

33 Even looking at the Fraser Institute scores over time, it is not clear what to take away from year-to-year volatility in their scores for a given school. The <bref [box id= Noise or News.pdf] $>$ online appendix provides some examples of these volatilities, which can only add to parents' confusion. 
challenge (Ladd and Walsh 2002; Hægeland et al. 2004; Mizala, Romoguera, and Urquiola 2007). ${ }^{34}$

\section{Reference}

Allen, R., and S. Burgess. 2013. "Evaluating the Provision of School Performance Information for School Choice." Economics of Education Review 34: 175-90.

Altonji, J. G., and C. R. Pierret 2001. Employer Learning and Statistical Discrimination, The Quarterly Journal of Economics, 116 (1): 313-50.

B.C. Ministry of Education. 2001. "Interpreting and communicating Foundation Skills Assessment Results 2001,” Available at: http://www.bced.gov.bc.ca/assessment/fsa/ pdfs/01interpret.pdf

Becker, G. S. 1995. "Human capital and poverty alleviation," World Bank Human Resource and Operation Policy Working Paper Number 52. Washington, DC.

Belfield, C. R., and H. M. Levin. 2003. "The Effects of Competition on Educational Outcomes: A Review of US Evidence." Review of Educational Research 72 (2): 279-341.

Bifulco, R., and H. F. Ladd. 2006. "The Impacts of Charter Schools on Student Achievement: Evidence from North Carolina." Journal of Education Finance and Policy 1 (1): 778-820.

Black, S. E. 1999. "Do Better Schools Matter? Parental Valuation of Elementary Education." Quarterly Journal of Economics 114 (2): 577-99.

Booker, K., S. M. Gilpatric, T. Gronberg, and D. Jansen. 2007. "The Impact of Charter School Attendance on Student Performance." Journal of Public Economics 91 (5): 849-76.

Borland, M. V., and R. M. Howsen. 1992. "Student Academic Achievement and the Degree of Market Concentration in Education." Economics of Education Review 11 (1): 31-9.

Chay, K. Y., P. J. McEwan, and M. Urquiola. 2005. "The Central Role of Noise in Evaluating Interventions That Use Test Scores to Rank Schools." American Economic Review 95 (4): 1237-58.

Chernew, M., G. Gowrisankaran, and D. P. Scanlon. 2008. Learning and the Value of Information: Evidence from Health Plan Report Cards, Journal of Econometrics, 144 (1): 156-74.

Cowley, P., and S. T. Easton. 2008. Report Card on British Columbia's Elementary Schools: 2003 Edition. Vancouver, BC: Fraser Institute.

Cullen, J. B., B. Jacob, and S. Levitt. 2005. "The Impact of School Choice on Student Outcomes: An Analysis of the Chicago Public Schools." Journal of Public Economics 89 (5-6): 729-60.

Cullen, J. B., B. Jacob, and S. Levitt. 2006. "The Effect of School Choice on Participants: Evidence from Randomized Lotteries." Econometrica 74 (5): 1191-230.

Dee, T. S. 1998. "Competition and the Quality of Public Schools." Economics of Education Review 17 (4): 419-27.

34 Building upon the work by Mark McClellan and Douglas Staiger (1999) in rating hospital performance, Kane and Staiger (2001) propose a filtered estimation to generate a more reliable measure of school achievement over time by exploiting the time-series dimension of them. However, one main disadvantage of using such techniques to produce more reliable measures of school performance is that they are much less transparent. 
Erdem, T., and M. P. Keane. 1996. Decision-Making Under Uncertainty: Capturing Dynamic Brand Choice Processes in Turbulent Consumer Goods Markets. Marketing science, 15 (1): 1-20.

Feldt, L. S., and R. L. Brennan. 1989. Reliability in Educational Measurement, 3rd edn. New York, NY: American Council on Education.

Figlio, D., and M. E. Lucas. 2004. "What's in a Grade? School Report Cards and the Housing Market." American Economic Review 94 (3): 591-604.

Fiske, E. B., and H. F. Ladd. 2001. When Schools Compete: A Cautionary Tale. Washington, DC: Brookings Institution Press.

Fiva, J. F., and L. J. Kirkebøen. 2010. "Information Shocks and the Dynamics of the Housing Market." American Economic Review 113 (3): 525-52.

Fraser Institute. 2015. Who We Are. Available at: http://www.fraserinstitute.org/aboutus/ whowe-are/overview.aspx

Friedman, M. 1955. "The Role of Government in Education." In Economics and the Public Interest, edited by R. A. Solo, Piscataway, N): Rutgers University Press.

Friesen, J., B. C. Harris, and S. Woodcock (2013) "Open Enrolment and Student Achievement." Working Paper No. 126. Vancouver BC: Canadian Labour Market and Skills Researcher Network.

Friesen, J., M. Javdani, J. Smith, and S. Woodcock. 2012. "How Do School 'Report Cards' Affect School Choice Decisions?” Canadian Journal of Economics 45 (2): 784-807.

Gibbons, S. and S. Machin. 2003. Valuing English Primary Schools, Journal of Urban Economics 53: 197-219.

Hægeland, T., L. J. Kirkebøen, O. Raaum, and K. G. Salvanes. 2004. “Marks across lower secondary schools in Norway: What can be explained by the composition of pupils and school resources?" Report 2004/11. Oslo-Kongsvinger: Statistics Norway.

Hanushek, E. A., J. F. Kain, and S. G. Rivkin. 2004. "Disruption Versus Tiebout Improvement: The Costs and Benefits of Switching Schools." Journal of Public Economics 88 (9-10): 1721-46.

Hastings, J., R. Van Weelden, and J. Weinstein. 2007. "Preferences, information and parental choice behavior in public school choice.” NBER Working Paper No.12995. National Bureau of Economic Research.

Hastings, J., and J. Weinstein. 2008. "Information, School Choice and Academic Achievement: Evidence from Two Experiments.” Quarterly Journal of Economics 123 (4): 1373-414.

Hoxby, C. M. 2003. "School Choice and School Productivity (or Could School Choice Be Atide That Lifts All Boats?" In The Economics of School Choice, edited by C. Hoxby, Chicago, IL: The University of Chicago Press.

Hoxby, C. M., and S. Murarka. 2007. "Charter schools in New York City: Who enrolls and how they affect their students' achievement.” No. w14852. National Bureau of Economic Research.

Hoxby, C. M., and J. E. Rockoff. 2005. The Impact of Charter Schools on Student Achievement. Cambridge, MA: Department of Economics, Harvard University.

Hsieh, C.-T., and M. Urquiola. 2006. "The Effects of Generalized School Choice on Achievement and Stratification: Evidence from Chile's Voucher Program." Journal of Public Economics 90 (8): 1477-503.

Ichino, A., and E. Moretti. 2009. Biological Gender Differences, Absenteeism, and the Earnings Gap, American Economic Journal: Applied Economics 1 (1): 183-218.

Kane, T. J., and D. O. Staiger. 2001. "Improving School Accountability Measures." National Bureau of Economic Research Working Paper No. 8156. 
Kane, T. J., and D. O. Staiger. 2002a. "Volatility in School Test Scores: Implications for TestBased Accountability Systems." Brookings Papers on Education Policy 5: 235-83.

Kane, T. J., and D. O. Staiger. 2002b. "The Promises and Pitfalls of Using Imprecise School Accountability Measures." Journal of Economic Perspectives 16 (4): 91-114.

Kane Thomas, J., D. O. Staiger, and S. K. Reigg. 2006. "School Quality, Neighborhood and Housing Prices: The Impacts of School Desegregation." American Law and Economics Review 8 (2): 183-212.

Kane Thomas, J., D. O. Staiger, and G. Samms. 2003. "School accountability ratings and housing values," Brookings-Wharton Papers on Urban Affairs: 83-137.

Ladd, H. F., and R. P. Walsh. 2002. "Implementing Value-Added Measures of School Effectiveness: Getting the Incentives Right." Economics of Education Review 21 (1): 1-17.

Lai, F., E. Sadoulet, and A. de Janvry. 2009. "The Adverse Effects of Parents' School Selection Errors on Academic Achievement: Evidence from the Beijing Open Enrollment Program." Economics of Education Review 28 (4): 485-96.

Lange, F. 2007. The Speed of Employer Learning, The Journal of Labor Economics, 25 (1): 1-34.

Manski, C. F. 1992. "Educational Choice (Vouchers) and Social Mobility." Economics of Education Review 11 (4): 351-69.

Mayer, D. P., P. E. Peterson, D. E. Myers, C. C. Tuttle, and W. G. Howell. 2002. "School Choice in New York City after Three Years: An Evaluation of the School Choice Scholarships Program.” Washington, DC: Mathematica Policy Research, Inc., Final Report, February 19.

McClellan, M., and D. Staiger. 1999. "The Quality of Health Care Providers," National Bureau of Economic Research Working Paper No. 7327.

Misra, K., P. W. Grimes, and K. E. Rogers. 2012. "Does Competition Improve Public School Efficiency? A Spatial Analysis.” Economics of Education Review 31 (6): 1177-90.

Mizala, A., P. Romoguera, and M. Urquiola. 2007. "Socioeconomic Status or Noise? Tradeoffs in the Generation of School Quality Information.” Journal of Development Economics 84 (1): 61-75.

Moretti, E. 2011. Social Learning and Peer Effects in Consumption: Evidence from Movie Sales. The Review of Economic Studies, 78 (1): 356-93.

Ries, J., and T. Somerville. 2010. "School Quality and Residential Property Values: Evidence from Vancouver Rezoning." The Review of Economics and Statistics 92 (4): 928-44.

Sass, T. R. 2006. "Charter Schools and Student Achievement in Florida." Education Finance and Policy 1 (1): 91-122.

Witte, J., D. Weimer, A. Shober, and P. Schlomer. 2007. "The Performance of Charter Schools in Wisconsin." Journal of Policy Analysis and Management 26 (3): 557-73.

Woodcock, S. D. 2010. Heterogeneity and Learning in Labor Markets, The B.E. Journal of Economic Analysis \& Policy (Advances) 10 (1): Article 85.

Wolf, P., B. Gutmann, M. Puma, L. Rizzo, N. Eissa, and M. Silverberg. 2007. "Evaluation of the DC Opportunity Scholarship Program: Impacts after One Year." U.S. Department of Education, Institute of Education Sciences. Washington, DC: U.S. Government Printing Office. 